\title{
Metastasectomy in a lung graft using high-flow venovenous extracorporeal lung support in a patient after single lung transplantation
}

Bassam Redwan, MD, ${ }^{\mathrm{a}}$ Stephan Ziegeler, MD, PhD, ${ }^{\mathrm{b}}$ Nicolas Dickgreber, $\mathrm{MD},{ }^{\mathrm{c}}$ and

Stefan Fischer, MD, MSc, PhD, ${ }^{\mathrm{a}}$ Ibbenbueren, Germany

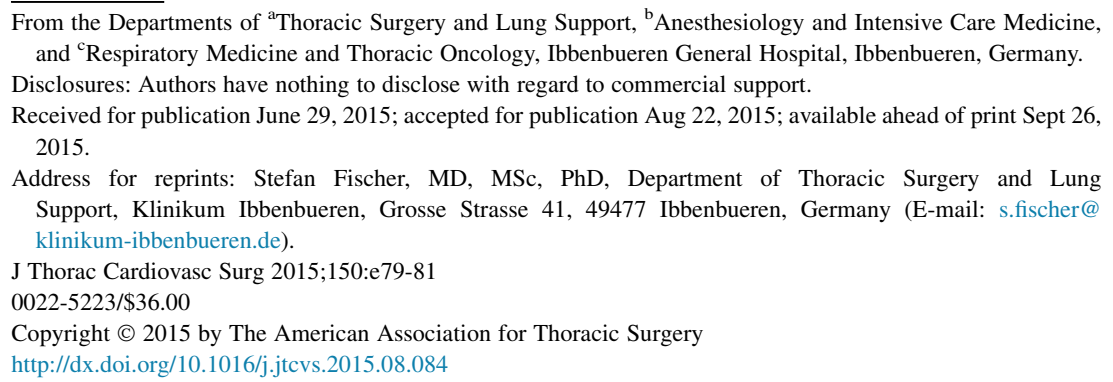

The intraoperative application of extracorporeal lung support (ECLS) is a modern concept in general thoracic surgery. So far, ECLS has been used mainly during complex tracheabronchial procedures or resection of locally advanced thoracic malignancies with invasion of the heart or great vessels. ${ }^{1,2}$

Recently, our group has reported the safe and effective intraoperative application of low-flow venovenous ECLS using a singular double-lumen cannula for pulmonary resections in patients with severely impaired pulmonary function.

We report the intraoperative application of high-flow venovenous ECLS for pulmonary graft metastasectomy in the transplanted lung in a patient with end-stage pulmonary fibrosis after single lung transplantation 8 years ago.

\section{CASE SUMMARY}

A 67-year-old male patient presented with 4 pulmonary masses in the upper lobe of his left lung graft. Eight years before, he had received left-sided single lung transplantation

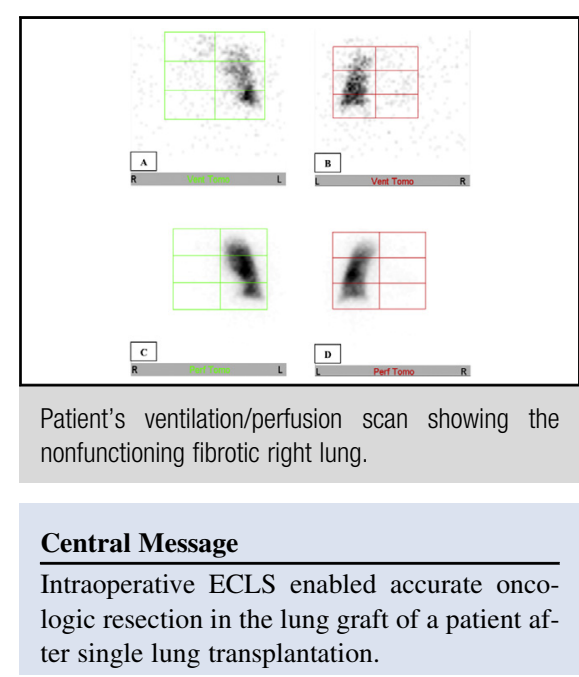

See Editorial Commentary page e81.

because of pulmonary fibrosis. In 2014, squamous cell carcinoma of the urinary bladder was diagnosed, and radical cystoprostatectomy with extended pelvic lymph node dissection and ileal conduit urinary diversion was performed.

In the current follow-up, the pulmonary masses demonstrated increased F-18 fluorodeoxyglucose uptake on positron emission tomography imaging (Figure 1). Therefore, metastases of the urinary bladder carcinoma were suspected. The ventilation/perfusion scanning

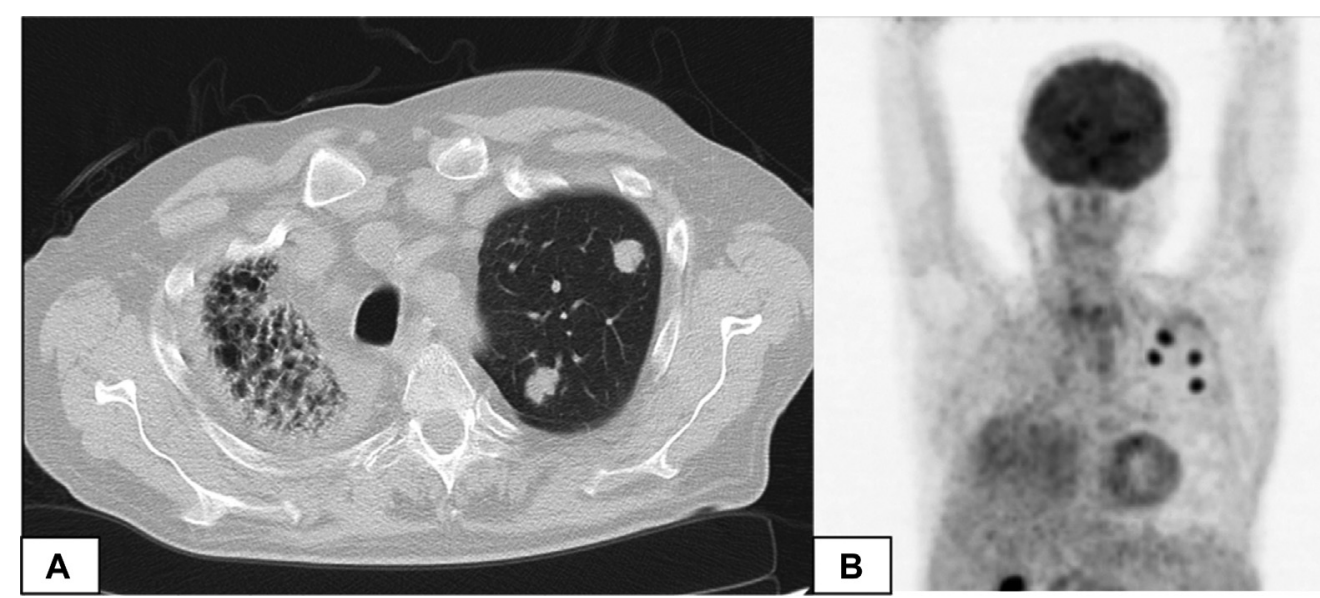

FIGURE 1. Chest computed tomography (A) and positron emission tomography scan (B) demonstrating an increased F-18 fluorodeoxyglucose uptake of the pulmonary masses in the left upper lobe. Note the fibrotic destroyed right lung. 

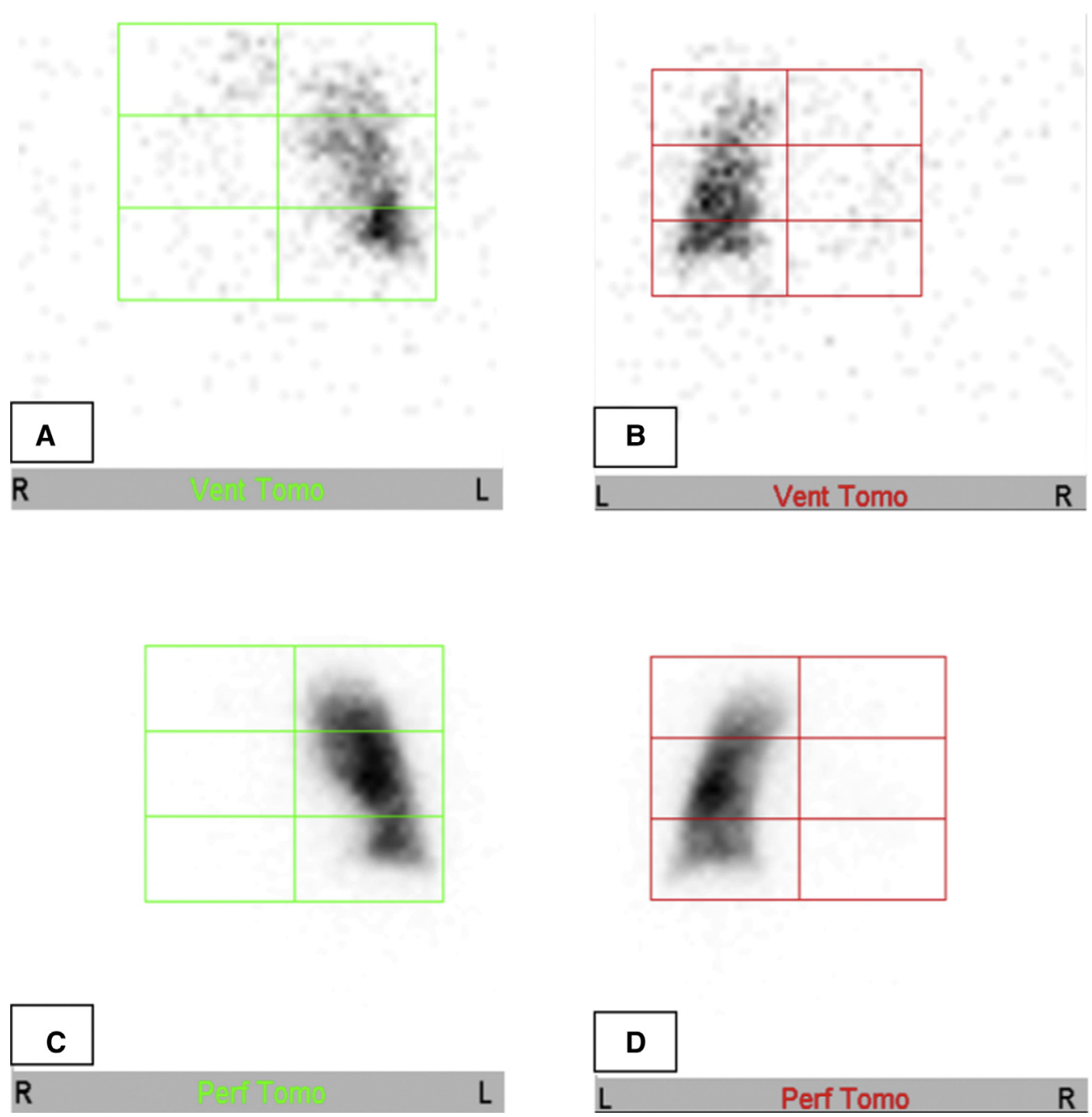

FIGURE 2. Ventilation (A and $B)$ and perfusion $(C$ and $D)$ scan of the patient showing the nonfunctioning fibrotic right lung.

revealed a nonfunctioning fibrotic right lung with a residual perfusion of $3 \%$ and ventilation of $11 \%$ (Figure 2 ).

After multidisciplinary discussion of the case at our local thoracic malignancies board, pulmonary metastasectomy was indicated. Because of the nonfunctioning fibrotic right lung, conventionally performed intraoperative single lung ventilation was impossible. Therefore, the application of intraoperative ECLS was considered. For this purpose, percutaneous femoral-jugular cannulation of the right femoral vein (Venous HLS Cannula 25F, Maquet, Rastatt, Germany) and right jugular vein (NovaPort One 21F, Novalung, Heilbronn, Germany) was performed. Highflow venovenous ECLS was initiated by the Interventional Lung Assist active system (Novalung) with a mean flow of $3.5 \mathrm{~L} / \mathrm{min}(3-4 \mathrm{~L} / \mathrm{min})$ and a sweep gas flow of $5 \mathrm{~L} / \mathrm{min}$ to establish transmembranous gas exchange. Subsequently, the patient was positioned onto his right side and the chest was entered through a left-sided lateral thoracotomy. ECLS support enabled complete apnea for 50 minutes, resulting in optimal atelectasis of the lung graft. Extended wedge resection of all 4 metastases in the left upper lobe was performed. ECLS was removed at the end of the procedure, and the patient was extubated in the operation room. The postoperative course was prolonged because of marked peripheral edema but was otherwise uneventful. The patient was discharged on postoperative day 21 for further rehabilitation. Histopathologic investigation revealed complete resection of 4 metastases of the urinary bladder carcinoma without lymph node invasion.

\section{CONCLUSIONS}

In cases of anticipated difficulties of conventional single lung ventilation, intermittent ventilation during surgery is often required to maintain sufficient gas exchange. However, this interferes with the atelectatic state and may impair the oncologic accuracy of the resection during metastasectomy. Intraoperative application of high-flow venovenous ECLS enabled the safe performance of pulmonary metastasectomy in this unique case. By avoiding intermittent ventilation, optimal atelectasis of the operated 
lung was achieved. Thus, accurate oncologic resection was enabled.

\section{References}

1. Lang G, Ghanim B, Hotzenecker K, Klikovits T, Matilla JR, Aigner C, et al. Extracorporeal membrane oxygenation support for complex tracheo-bronchial procedures dagger. Eur J Cardiothorac Surg. 2015;47: 250-6.

2. Lang G, Taghavi S, Aigner C, Charchian R, Matilla JR, Sano A, et al Extracorporeal membrane oxygenation support for resection of locally advanced thoracic tumors. Ann Thorac Surg. 2011;92:264-70.

3. Redwan B, Semik M, Dickgreber N, Ziegeler S, Fischer S. Single site cannulation veno-venous extracorporeal lung support during pulmonary resection in patients with severely compromised pulmonary function. ASAIO J. 2015;61:366-9.

\title{
EDITORIAL COMMENTARY
}

\section{Placing technique before judgment?}

\author{
John H. Calhoon, MD
}

From the Department of Surgery, University of Texas Health Science Center at San Antonio, San Antonio, Tex. Disclosures: Author has nothing to disclose with regard to commercial support.

Received for publication Aug 25, 2015; accepted for publication Aug 25, 2015; available ahead of print Sept 19, 2015.

Address for reprints: John H. Calhoon, MD, Department of Surgery, University of Texas Health Science Center,

San Antonio, 7703 Floyd Curl Dr, San Antonio, TX 78229 (E-mail: calhoon@uthscsa.edu).

J Thorac Cardiovasc Surg 2015;150:e81-2

$0022-5223 / \$ 36.00$

Copyright (C) 2015 Published by Elsevier Inc. on behalf of The American Association for Thoracic Surgery http://dx.doi.org/10.1016/j.jtcvs.2015.08.074

The authors ${ }^{1}$ describe a new application for a type of extracorporeal membrane oxygenation support of the cardiopulmonary process. The article is clear and certainly adds to the array of possibilities available to cardiothoracic surgeons in our quest to improve the health and lives of our patients. Because it is a case report, we have no long-term followup on the patient and no series to review to help us gauge the efficacy of this treatment modality in the long term.

Malignancy after lung transplantation is fairly common, occurring in approximately $4 \%$ of patients in the first year, and in $25 \%$ by year 10 . Indeed, it is a common (nearly $10 \%$ after the first year) cause of death after transplantation. Not much can be found on review, regarding bladder cancer in the post-lung transplantation patient, but hematologic malignancy is the most common form of posttransplantation cancer, followed by skin and then other malignancies.

The most accepted form of treatment for malignancy after transplantation is careful reduction in immunosuppression, and it has mixed results. ${ }^{2}$ Whether this approach was pursued was not addressed in the authors' report, but hopefully it was an important part of their treatment strategy. One should never consider the age, but rather the mileage, on a particular patient. It is easy to assume a 67-year-old man, now 8 years beyond a lung transplantation, who developed extensive bladder cancer requiring an exhaustive resection no more than a year before, and now has 4 discrete metastatic lung lesions, has accumulated more miles than

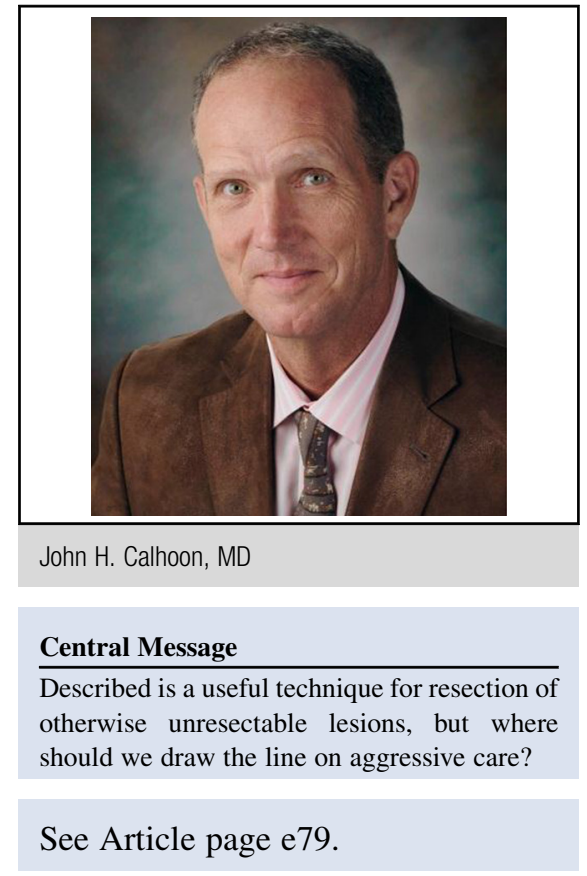

most his age. Despite fine efforts, it would be suspected that, statistically, this case has a fairly low chance of being cured; the patient came with a significant risk, and quite realized morbidity of 3 weeks of hospitalization.

In addition to the risk and morbidity, we know concern exists for the immunomodulation associated with cardiopulmonary bypass, and presumably extracorporeal membrane oxygenation, which may have further facilitated the spread of the disease or inhibited the patient's own metastatic disease defenses. At his age (mileage), the ability of this patient to return to a functional existence after such a procedure is questionable. The purpose of this editorial is to 